\title{
Group-size preference during circadian hiding in nymph and adult female German cockroaches (Blattella germanica L.)
}

\author{
RICHARD E. BAKER, RONALD BURKE, and MICHAEL H. FIGLER \\ Towson State University, Towson, Maryland 21204
}

\begin{abstract}
Group-size preference in circadian hiding behavior by female $B$. Germanica was investigated by providing first-instar nymphs and adults with numerous similar hiding shelters. The cockroaches were given the opportunity to aggregate, space, or distribute themselves among the shelters in any fashion. Results indicated that both nymphs and adults preferred to hide either alone or in small groups of six or less. However, nymphs chose smaller groups than adults. The results are discussed in terms of circadian vs. escape hiding. It is also suggested that groupsize preference may partially depend on population density, since cockroaches aggregate rather than space themselves as population density increases.
\end{abstract}

Circadian hiding is defined as the daily pattern of seeking protective shelter from predators and dehydration, as opposed to escape hiding from sudden perturbations of light or vibrations (Cornwell, 1968). It is estimated that cockroaches spend at least $75 \%$ of their time hiding (Cornwell, 1968), with peak activity levels occurring during the early hours of darkness (Harker, 1960; Lipton \& Sutherland, 1970).

Berthold and Wilson (1967) investigated the hiding space selection process by giving Blattella germanica a choice of hiding places that varied in width from 1.6 to $12.7 \mathrm{~mm}$. It was found that $85 \%$ of the insects selected compartments $4.8 \mathrm{~mm}$ wide. They also found that if B. germanica are given a choice of hiding places, $83 \%$ select previously occupied areas. Evidence reported by Ishii (1970) and Ishii and Kuwahara (1968) suggests that this preference may be mediated by an aggregation pheromone present in the feces. Wharton, Miller, and Wharton (1954) have distinguished between aggregation pheromones and sex pheromones in Periplaneta americana. Females produce both pheromones, with the aggregation pheromone eliciting approach behavior in males. However, the aggregation pheromone itself does not elicit male sexual behavior (Block \& Bell, 1974; Wharton et al., 1954). No mention was made in these studies as to whether females are also attracted to this female-produced aggregation pheromone. Bell, Burk, and Sams (1973) found that nymph and adult $P$. americana of both sexes secrete pheromones and follow pheromonal substances deposited in feces. It was not determined in that study whether females follow scents left by males or females.

Although some factors that affect aggregation have

Reprint requests should be sent to Michael H. Figler, Department of Psychology, Towson State University, Towson, Maryland 21204. been investigated, no research is known that has studied group-size preference of female cockroaches during circadian hiding. The purpose of the present study was to ascertain what group sizes are formed by adult females and first-instar female $B$. germanica when provided with numerous identical shelters. Nymphs and adults were used to uncover any developmentally related changes in aggregation.

\section{METHOD}

\section{Subjects}

Eighty female $B$. germanica cockroaches, 40 adults and 40 first-instar nymphs, were purchased from the American Biological Institute, Baltimore, Maryland. Subjects were initially housed in glass or plastic containers and acclimated to a $12: 12 \mathrm{~h}$ light-dark cycle prior to testing. Temperature was held between $27^{\circ} \mathrm{C}$ and $30^{\circ} \mathrm{C}$ (Gunn, 1935), and relative humidity ranged from $50 \%$ to $60 \%$ (Haber, 1926). All handling and counting were facilitated by anesthetizing the insects with $\mathrm{CO}_{2}$, as described by Smith (1966). Subjects received ad-lib water and Purina Dog Chow, but on the 4 th day of adaptation, the food was removed.

\section{Apparatus}

The apparatus was a 60.5 -cm-diam open field with 60 individual U-Vex hiding compartments on the periphery (see Figure 1). Each compartment was $17.5 \mathrm{~cm}$ long, $1 \mathrm{~cm}$ wide on the inside, $1.25 \mathrm{~cm}$ wide on the outside, and $7.5 \mathrm{~cm}$ high, with a single 4.8-mm-diam entrance from the open field. The number of compartments exceeded the number of subjects so that they would not be forced into groups simply because unoccupied shelters were unavailable. Also, the compartments were large enough to simultaneously accommodate all 40 cockroaches. Compartments were painted flat black and covered with a black lid. Vertical surfaces of the apparatus and the bottom of the lid were coated with a thin film of petroleum jelly to reduce escape from the apparatus.

\section{Procedure}

Subjects were tested for locomotor ability and reactivity on Day 5 by prodding with a small brush. They were then moved to the apparatus $15 \mathrm{~min}$ prior to the onset of darkness and were released immediately after the onset of darkness, which is the 


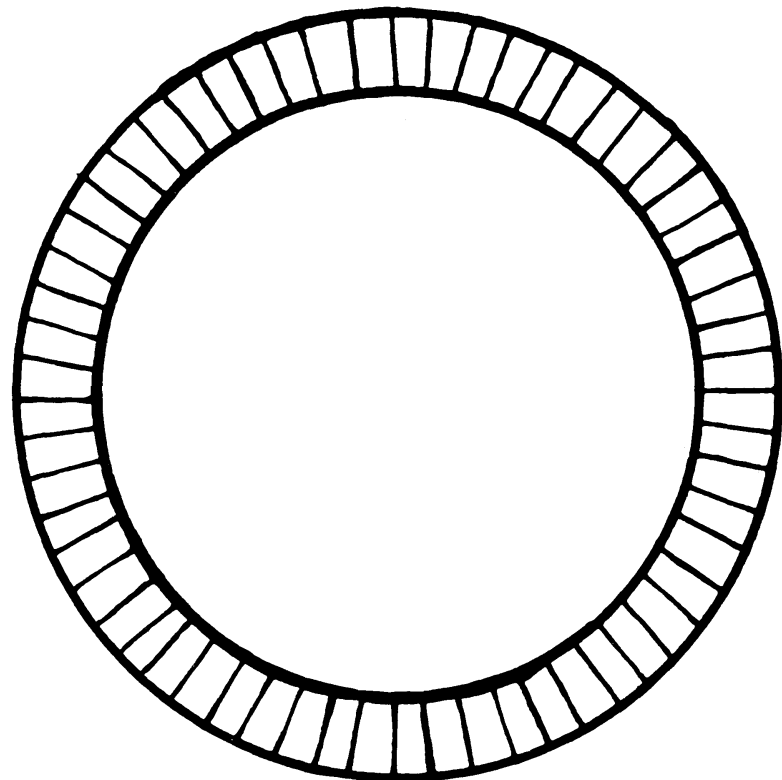

Figure 1. An open-field apparatus with 60 peripheral hiding compartments.

most active time in their circadian cycle (Harker, 1960; Lipton \& Sutherland, 1970). Food and water were provided in the center of the open field in order to allow the 24-h food-deprived cockroaches to feed before hiding. The following morning, the cockroaches were anesthetized, and the number of subjects occupying each compartment or the open field were counted. The above procedure was used for the adults and was repeated with the nymphs after the apparatus was cleaned.

\section{RESULTS}

The frequency distribution of group sizes chosen by adult cockroaches revealed that adult B. germanica preferred small group sizes (see Figure 2).

Among the 39 subjects in the hiding compartments, $28 \%$ chose to be alone, $21 \%$ chose group sizes of 2 , no subjects chose group sizes of $3,10 \%$ chose group sizes of $4,26 \%$ chose group sizes of 5 , and $15 \%$ chose group sizes of 6 . No subjects chose a group size larger than six, and one subject did not hide at all. The experimental distribution was found to be significantly different from a random distribution, using the Kolmogorov-Smirnov one-sample test $(\mathrm{D}=.846, \mathrm{p}<.01)$ (Siegel, 1956).

The frequency distribution of group-size preference for the nymphs is presented in Figure 3. The nymphs' distribution was also found to be significantly different from a random distribution using a Kolmogorov-Smirnov one-sample test $(D=.846, p<.01)$. First-instar nymphs also showed a preference for small groups. The compartments were utilized by 26 of the 40 nymphs; a few escaped from the apparatus, and the remainder were scattered throughout the open field. Among these 26 hiding nymphs, $46 \%$ chose a group size of $1,38 \%$ chose a group size of 2 , no subject chose a group size of 3 , and $15 \%$ chose a group size of 4 . No subjects chose a group size larger than four.
In order to determine the relation between developmental stage (nymph or adult) and group-size perference, a contingency coefficient was calculated (Siegel, 1956). Since many cell frequencies were too low, Group Sizes 1-3 were pooled and compared with Group Sizes 4-6 to satisfy statistical criteria. The contingency coefficient between developmental stage and group-size preference was +.31 , a significant finding $\left[\chi^{2}(1)=7.16\right.$, $\mathrm{p}<.01]$. Therefore, nymphs chose significantly smaller group sizes than adults. The most frequent choice for both nymphs and adults was to hide alone. Neither adults nor nymphs aggregated in a group size of three, although the reason for this patterning is not known.

\section{DISCUSSION}

This study was performed to ascertain group sizes formed during circadian hiding. Research by Berthold and Wilson (1967) and Ishii and Kuwahara (1968) indicate that cockroaches are attracted to odors and hide in large groups. Odors were equivalent in all the hiding compartments at the beginning of the present experiment; however, after the first cockroach entered a compartment, the odors were no longer equivalent. According to Ishii and Kuwahara's findings and those of Berthold and Wilson, cockroaches that hid later in the present study should have

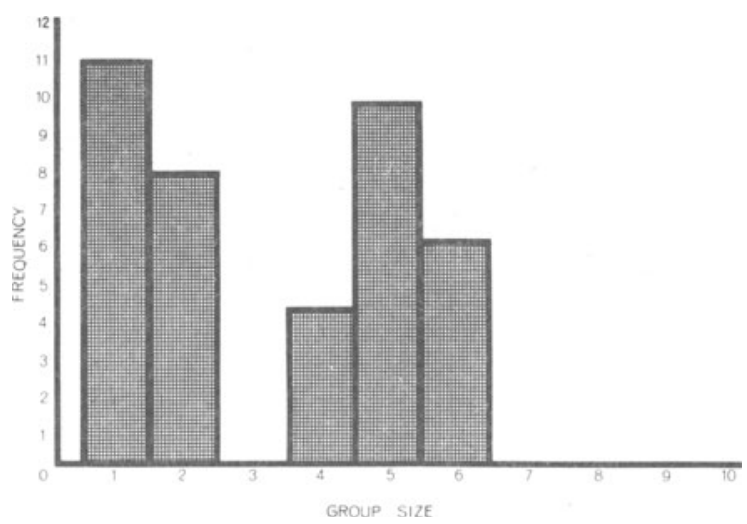

Figure 2. Frequency of adult females hiding in various group sizes.

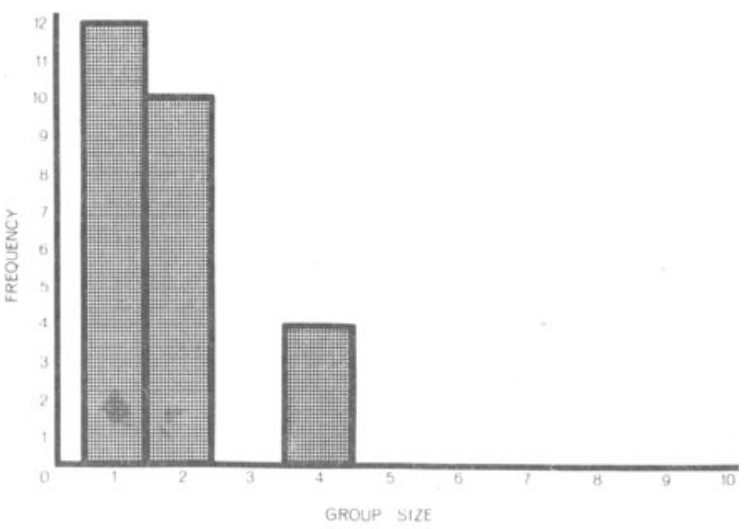

Figure 3. Frequency of nymph females hiding in various group sizes. 
preferred the occupied shelters and formed large groups instead of small ones. An important difference between the present study and those of Berthold and Wilson and Ishii and Kuwahara is the variable of circadian vs. escape hiding. Their studies did not specify whether they were investigating escape hiding or circadian hiding, which may be an important distinction. In an emergency situation, pheromones may act as an olfactory cue to guide cockroaches to suitable shelter quickly. However, in a circadian situation in which speed is not essential, other factors such as territoriality may be more important than pheromonal cues.

Another difference between the Ishii and Kuwahara (1968) study and the present one is that of population density. Ewing (1972) found that in low population densities, cockroaches form hierarchies and distribute themselves in territories; however, high population densities disrupt the hierarchical and territorial structures, resulting in the cockroaches' crowding themselves into aggregations and therefore leaving wide unoccupied space. Ishii and Kuwahara performed their experiment with a higher population density than that in the present study. This variable may explain why they found clumping, whereas the present study showed spacing. Also, a female-produced aggregation pheromone has been shown to attract males (Block \& Bell, 1974; Wharton et al., 1954), but it may not attract other females. Thus, the small group sizes of both nymph and adult females found in the present study may have resulted from the failure of the female-produced aggregation pheromone to attract other females.

Further research is needed to verify the hypothesis that pheromones operate as olfactory cues leading to hiding spaces in escape conditions to a greater extent than they do in circadian hiding conditions. If Ishii and Kuwahara's (1968) study is replicated comparing escape and circadian hiding situations, more cockroaches should aggregate to pheromones in the escape hiding situation than in the circadian situation. Also, the hypothesis that high population densities lead to aggregation rather than to spacing could be tested by replicating the present study and manipulating population density. In such a paradigm, higher densities would be expected to produce larger group-size preferences.

\section{REFERENCES}

Bell, W. J., Burk, T., \& Sams, G. R. Cockroach aggregation pheromone: Directional orientation. Behavioral Biology, 1973, 9, 251-255.

Berthold, R., \& Wilson, B. R. Resting behavior of the German cockroach, Blattella germanica. Annals of the Entomological Society of America, 1967, 60, 347-351.

BLOCK, E. F., \& BELL, W. J. Ethometric analysis of pheromone receptor function in cockroaches. Journal of Insect Physiology, 1974, 20, 993-1003.

Cornwell, P. B. The cockroach (Vol. 1). London: Hutchinson, 1968.

Ewing, L. S. Hierarchy and its relation to territory in the cockroach Nauphoeta cinerea. Behaviour, 1972, 42, 152-174.

GunN, D. L. The temperature and humidity relations of the cockroach: III. A comparison of temperature preference rates of desiccation and respiration of Periplaneta americana, Blattella orientalis and Blattella germanica. Journal of Experimental Biology, 1935, 12, 185-190.

HABER, V. R. The tracheal system of the German cockroach, Blattella germanica Linnaeus. Bulletin of the Brooklyn Entomological Society, 1926, 21, 61-92.

HARKER, J. E. The effects of perturbations in the environmental cycle of the diurnal rhythm of the activity of Periplaneta americana Linnaeus. Journal of Experimental Biology, 1960, 37, 154-163.

IsHII, S. Aggregation of the German cockroach Blattella germanica. In D. L. Woods, R. M. Silverstein, \& M. Nakajima (Eds.), Control of insect behavior by natural products. New York: Academic Press, 1970.

IshiI, S., \& KuwaharA, Y. Aggregation of German cockroach (Blattella germanica) nymphs. Experientia, 1968, 24, 88-89.

Lipton, G. R., \& Sutherland, D. J. Activity rhythms in the American cockroach, Periplaneta americana. Journal of Insect Physiology, 1970, 16, 1555-1566.

SiEgel, S. Nonparametric statistics for the behavioral sciences. New York: McGraw-Hill, 1956.

Sмiтh, D. J. Cockroaches. In C. N. Smith (Ed.), Insect colonization and mass production. New York: Academic Press, 1966.

Wharton, D. R. A., Miller, G. L., \& Wharton, M. D. The odorous attractant of the American cockroach Periplaneta americana L.: I. Quantitative aspects of the response to the attractant. Journal of General Physiology, 1954, 37, 461-469.

(Received for publication February 4, 1980.) 